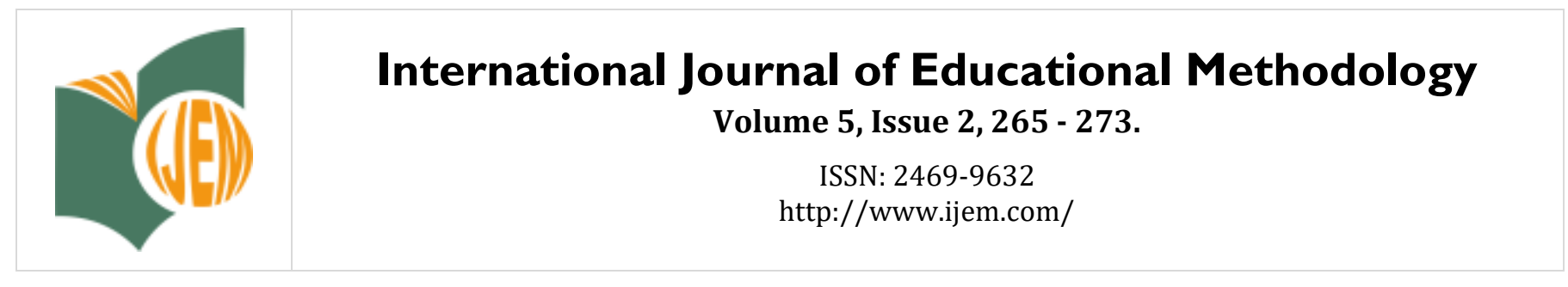

\title{
Investigation of Third Grade Students' Views on Media Literacy
}

\author{
Belgin Arslan-Cansever * \\ Ege University, TURKEY
}

Received: March 18, $2019 \cdot$ Revised: April 17, 2019 - Accepted: May 6, 2019

\begin{abstract}
The purpose of this study is to examine the views of nine years old students about media literacy and media literate. Phenomenology approach was used qualitative research designs in the research. The study group consisted of 12 (7 girls, 5 boys) third grade students from two different primary schools in Bayrakli, Izmir, Turkey. Research data were collected through interviews. In these interviews, a semi-structured interview form was used. Content analysis was used to analyze the data. Research findings are grouped under three themes: The meaning of media literacy, Characteristics of media literate and Being able to define themselves as being media literates or not. The findings showed that students mostly defined media literacy as "having a time limit in the use of media tools" and "critical view to the media". According to students, the media literate is " the one who uses the media for educational purposes" and as "critics".
\end{abstract}

Keywords: Media literacy, media literate, primary school students.

To cite this article: Arslan-Cansever, B. (2019). Investigation of third grade students' views on media literacy. International Journal of Educational Methodology, 5(2), 265-273. https://doi.org/10.12973/ijem.5.2.265

\section{Introduction}

The relationship of the child with the media begins in infancy. There are studies showing that this first meeting with television mostly took place around 4 to 6 months (Field, Muir, Pilon, Sinclair \& Dodwell, 1980). The child begins to understand television at around two and a half years of age (Anderson, 2013). It is known that the tendency of the child to show interest in media content has increased significantly in early childhood (3-6 years) (Valkenburg \& Vroone, 2004). The phase called school years covers the age range of 7-11 years by some researchers (Piotrowski, Vossen \& Valkenburg, 2013) and 6-12 years by other researchers (Gander \& Gardiner, 2001). There is a higher rate of interaction with the media during the school years than in previous periods (Rideout, Foehr \& Roberts, 2010). In this context, it can be said that the media have an increasing importance in evaluating the leisure time of the child. The individual needs to be aware of all these messages coming from the media with different channels. This awareness can be achieved by educating the individual about media literacy and become media literate. Tan (2015) views media literacy as the only obstacle to the child's disappearance in the symbolic world of media content (p. 74). In this context, it is important to determine how children define themselves in their relations with the media. For this reason, it is thought that examining how media tools have a place in the child's world will be useful in forming the theoretical basis of the subject.

\section{The Place of Media in the Child's World}

Today, children's media is diversified with a wide range of media, including satellite/cable television, Internet, radio, MP3 players, computers, newspapers, video games, mobile phones, magazines and text messages (Gregory, 2013, p. 94). Research shows that the television, which was introduced for the first time in infancy, was also effective in school years. Television is in the first place in children's media preferences and has a share of $85 \%$ (Lindstrom \& Seybold, 2003). According to the Turkey Statistical Institute (TSI), 92.5\% of the Turkish children are watching television every day. $12.5 \%$ of this group watches television for an average of four hours per day (TSI, 2013). In another study Tyner (2009) reported that children were exposed to 5000 hours of television before they started school. This is important for children to begin to solve the high level of emotional and symbolic language on television. Postman (1994) argues that television is the most important media tool. This is explained by the fact that television has risen to the status of a top vehicle that directs information about the world as well as information about ways of knowing. The individual is

\footnotetext{
* Correspondence:

Belgin Arslan-Cansever, Ege University, Faculty of Education, Elementary School Department, Turkey.

$\triangle$ belgin.arslan.cansever@ege.edu.tr
} 
mainly directed by the television in the use of different mass media. They learn from television about which films should be watched, which books to read and which radio programs to listen. According to Piotrowski, Vossen and Valkenburg (2013), children's interest in interactive media during school years also increases. The mean age at which Turkish children start to use computers is 8 years of age, 9 years of age for using Internet and 10 years of age for using mobile phones. The results of the research conducted in 2013 in Denmark, Italy, Romania and England are also similar. As a matter of fact, the average age of Internet use in these countries is 8 years and the age of using mobile phones is about 9 years. Among these countries, the earliest years of using the Internet are in Denmark ( 7 years) and the earliest age for having mobile phones is in Denmark and Romania (9 years). Approximately half of the children in the 6-10 age group use the Internet in Turkey between three and ten hours a week. The purpose of these children is to play computer games (TIS, 2013). Children aged six and older watch different types of television programs, play various computer games and start using social media on the Internet (Anderson, 2013). There are many studies on what children have learned from both the educational and entertainment content of the media. Educational programs teach children literacy, mathematics, science and other skills. At the same time, children acquire spatial cognitive skills from both television and computer games. On the other hand, entertainment media, especially those with a violent content, are associated with children being aggressive in family and friendship relationships, having difficulty in school and weak reading skills (Anderson, 2013). Children around the age of eight watch television for approximately four hours a day, play video games for one hour and spend 20 minutes on social media sites (Rideout, Foehr \& Roberts, 2010). From the age of six, children are less interested in slow-paced educational programs, but they are interested in action and violence (Piotrowski, Vossen \& Valkenburg, 2013). In this context, it is possible to say that the media is an important part of the child's life. Different media options shape the child's daily life. The age at which children meet with the media and their duration of interaction vary according to age groups. Similarly, the media content that children are interested in differs with their age. Research in this field shows that interest in violence has increased. In this context, it is considered as a necessity to build up the media literacy consciousness in childhood.

\section{Media Literacy and Necessity of Media Literacy in Childhood}

Media literacy is in the focus of different disciplines such as education, communication, health and political science. Therefore, it is possible to find many definitions of media literacy in the literature. This concept is defined in the Media Literacy Glossary as "a critical thinking skill that gives viewers the ability to solve the meaning of information they receive and to make independent decisions about media content". Aufderheide (1993) and Hobbs (2004) defined media literacy as the ability to reach, analyze, evaluate, and communicate with messages in the media. Media literacy is shown as a vital skill of the 21st century. This skill also emphasizes the development of reality in the media, freedom of expression, knowledge acquisition and the development of critical criticism for citizenship and democracy. (Cetinkaya, 2008; Pekman, 2007; Tan, 2015). The mainstays of the media literacy definitions in the literature are accessing messages, analyzing messages, analyzing them critically and sharing them with others.

Cakir and Cakir (2010) stated that media had behavioral, attitudinal, cognitive, emotional and physiological effects on the individual. Behavioral effects are related to individual behaviors that are presented by media messages. Affective effects are that media messages shape the individual's beliefs and values. Cognitive effects are messages from the media that are shaping the individual's thoughts. Emotional effects are the emotions of fear, anxiety or enthusiasm on the individual. Physiological effects are the changes in stimulation and other physical reactions in the media consumer as a result of media messages. These effects that the media creates on individuals leave deep marks especially in children (Erturk \& Gul, 2006). Children identify themselves with cartoon heroes they meet through the media, sometimes they act like them, adopt the language, beliefs and values that they use. Sometimes they have a sense of fear against the character and are emotionally affected. There are studies that emphasize the importance and necessity of media literacy that paves the way for children to be conscious individuals in the face of media messages, arguing that the media has both positive and negative effects on children's cognitive and educational development (Anderson, 2013; Arslan-Cansever, 2013; Cetinkaya, 2008; Kincal \& Kartal, 2009). The increase in the duration and frequency of use of different media tools in childhood, written, oral and non-verbal messages coming from the media and the way children think and shape their behavior reveals the necessity of raising generations of media literate. Baker (2012, p.14) describes media literacy as "a lens for understanding and seeing the world". Nowadays, it is important that children are raised as individuals who are sensitive to media messages and who know how to protect themselves against negative messages and who question them in a critical approach. In this context, educating individuals in media literacy can be considered a necessity beyond the need of the age. It is important to know the characteristics of the media literate in the upbringing of the child as a media literate.

\section{Characteristics of the Media Literate}

Winahyu and Djono (2018, p. 364) describe media literate as "a person who acquires the media literacy ability, is considered as someone who capable of using process skills such as awareness, analysis, reflection, and action to understand the meaning." Koc (2016) states that media literate individuals have the ability to analyze and produce in oral language, reading and writing. European Media Literacy Center has listed the characteristics of the media literate as follows (Cited in Altun, 2010, p.20-21): 
- To be able to use media technologies effectively to reach, store, recover and share the content that will meet their individual and social needs and interests,

- Be able to make informed choices by accessing various media forms and content from different cultural and traditional sources,

- To understand how and why media content is produced,

- To be able to critically analyze the techniques, languages and rules of media and messages conveyed by the media.

- To be able to use the media creatively to explain and convey ideas, information and opinions,

- To be able to identify media content and services which may be unwanted, aggressive and harmful, avoiding and opposing them,

- To be able to use the media effectively while fulfilling his democratic rights and citizenship responsibilities.

According to Aufderheide (2001), media literacy refers to the qualifications to be present in the individual as decoding, evaluating, analyzing and producing printed and electronic media. Similarly, Tyner (1998) emphasizes the ability to produce information by analyzing media contents.

When the research in the field of media literacy are examined, the studies examining the views of children in primary school on media literacy are found to be limited. It is important to raise the awareness of the students in the primary school period as a media literate about the messages received from the media. In this context, it is important to determine the views of primary school students about media literacy and media literate. The research problem, "What are the views of nine-year-olds about media literacy?" has been determined. In this context, interview questions are prepared as follows:

1. What do you understand from the concept of media literacy '?

2. What are the characteristics of the media literate?

- What are the features?

- How to use the media?

3. Do you consider yourself a media literate?

- If the answer is yes, why?

- If the answer is no, why?

\section{Methodology}

Research Goal

The purpose of this study is to examine the opinions of the nine years old students about media literacy and media literate.

\section{Research Design}

The research is in the phenomenology pattern in the qualitative research tradition. In the phenomenology pattern, which is both a philosophical view and a research approach, it is possible to define the phenomena that we are aware of but do not have in-depth and detailed understanding in terms of the experiences of individuals or a group (Christensen, Johnson \& Turner, 2015; Creswell, 2009; Ersoy, 2016; Merriam, 2013). In this study, the phenomenology pattern was preferred because the views of primary school students on media literacy and media literate were tried to be understood and interpreted.

\section{Participants}

Considering the scope of the study and its duration, two primary schools in Bayrakli district were determined as random. Cluster sampling was used to determine the participants. This is because the purposeful sampling method allows for in-depth study of the situations in which rich information is thought to be found. In similar samples, the participants are close to each other and have very similar characteristics (Patton, 2014). Participant students were selected through systematic sampling. For this purpose, the class lists were taken from the school directorates were used. According to these lists, students who ended up with an odd number in each class and stated that they wanted to participate voluntarily were included in the study.

\section{Data Collection Tool}

Research data were collected through interviews with students through a semi-structured interview form. Interviews provide individuals with the opportunity to express the behaviors and feelings that they cannot observe. It helps them understand how they see the world, personal perspectives and experiences (Merriam, 2013; Patton, 2014). In this 
study, the reason why the interview method is preferred is to evaluate the students' opinions with the first hand data. A semi-structured form was used in interviews with students. The questions in the form have been prepared by the author who has studies in the field of media literacy. In order to determine the validity of the form, two field experts who have research in the field of media literacy were consulted in the field of assessment and evaluation. In accordance with the recommendations of the experts, the necessary corrections have been made and the form has been made ready for pre-application. The pilot study of the research was made with 3 students who were not included in the main practice. A question that was not fully understood in this application has been replaced by an alternative question. One question was clarified by adding probes. Thus, the form has been developed and finalized according to the results of the pre-application with expert opinions.

\section{Validity and Reliability Measures}

The measures related to the validity and reliability of the study were taken into consideration in terms of the features put forth by Merriam (1990) and Yin (1984) (Cited in Yildirim \& Simsek, 2008). In this context, in order to increase the validity of the research, the researcher tried to present the results in the research in a detailed, clear and concise manner. For the reliability of the study, the answers of the participant children to the questionnaire were examined by the researcher and the two field experts. In these studies, after the determination of the unity and separation clauses in the opinions, the percentage agreement proposed by Miles and Huberman (1994) was used. The formula is: "percentage of compromise $=$ [consensus $/ \mathrm{Na}$ (consensus) $+\mathrm{Nd}$ (disagreement) $]$ x 100". As a result of the calculation, the reliability of the study was calculated as $81 \%$. According to Miles and Huberman (1994), if the percentage of consensus exceeds $70 \%$, the study is considered reliable. As for this study, the coding reliability was accepted as reliable.

The researcher interviewed students in psychological counseling rooms in schools. The interviews lasted for about twenty minutes and were recorded by a voice recorder with the permission of the students. Later on, the audio recordings were transcript and ready for analysis.

\section{Analyzing of Data}

Content analysis was used to analyze the research data. Content analysis aims to reach the concepts and relations that can explain the data. Patton (2014), the basic meanings found in the analysis of data as a theme. This research data was also taken into consideration by taking the basic meanings and relations into consideration. The themes and encodings under each research question are presented in tables, views of the students are given, and then the tables are commented. Table 1 , shows the themes and codes obtained as a result of the research findings.

Table 1. Themes and codes of findings

\begin{tabular}{ll}
\hline Theme & Code \\
\hline & There is a time limit in the use of all media tools \\
The meaning of media literacy & Ability to look at the media critically \\
& To have the necessary information to make cartoons \\
& Ability to interpret the book \\
\hline & To know how to use media tools for educational purposes \\
& It is like as a critic \\
& To gain new knowledge and skills from media \\
& When he watches things, he asks, "Is this real?" \\
& He can do cartoon \\
\hline Being able to define himself/herself: I am a media & I am a media literate \\
literate / I am not a media literate & I'm not a media literate \\
\hline
\end{tabular}

\section{Findings/Results}

The views of the children who participated in the study were grouped under three themes. These are: the meaning of media literacy, characteristics of media literate and being able to define themselves as Media Literates or not.

The Meaning of Media Literacy

Students described media literacy within the framework of the definitions shown in Table 2.

Table 2. Media Literacy Definitions of Children

\begin{tabular}{ll}
\hline Media literacy definitions & f \\
\hline There is a time limit in the use of all media tools. & 4 \\
Ability to look at the media critically. & 3 \\
I do not know & 3 \\
To have the necessary information to make cartoons. & 1 \\
\hline
\end{tabular}


Ability to interpret the book.

1

When Table 2 is examined, it is seen that students define media literacy as in having a time limit in the use of all media tools and ability to look at the media with criticism. The fact that there is a time limit in the use of media tools has been revealed by the students from time to time as a problem with their parents. For example, Emirt, Melisa and Eren expressed their views on this subject:

"Whenever I want to watch television, my mother puts a time limit. She closes my cartoon before the end. That's when I get angry. (Emir)

"My mother puts a time limit on using mobile phone and the Internet. Thus, sometimes we argue." (Melisa)

"My father gives me half an hour while I play the computer. He gets angry when I go over this time and play the game for a long time. Actually, it's not my fault, time is passing very fast when you're playing a game on computer." (Eren)

Some of the students who defined media literacy by criticizing the media through criticism have explained the critical look of the media with the examples they give from advertisements:

"Sometimes I watch a toy advertisement that looks very good on television. I insist on buying it, but when we get the toy, it's not what it looks like in TV ads..." (Can)

"I don't like commercials between cartoons. It's been too long and I forget what I'm watching. Thus, I'm criticizing the advertisement." (Damla)

Another remarkable finding in Table 2 is that about one fourth of students cannot define media literacy. These students stated that they do not know media literacy.

Characteristics of the Media Literate

The views of children about media literate are shown in Table 3.

Table 3. Characteristics of the Media Literate

\begin{tabular}{lc}
\hline Characteristics of the Media Literate & $\boldsymbol{f}$ \\
\hline To know how to use media tools for educational purposes & 4 \\
It is like as a critic & 4 \\
To gain new knowledge and skills from media & 1 \\
When he watches things, he asks, "Is this real?" & 1 \\
He can do cartoon & 1 \\
I do not know & 1 \\
\hline
\end{tabular}

In Table 3, some of the students explained characteristics of the media literate by knowing how to use media tools for educational purposes. Some of the students' opinions are:

"I think the media literate knows very well how to use the Internet in assignments." (Derin)

"Media literate focuses on the research question while searching in a book." (Kaya)

Some of the students stated that media literate was like a critic.

"Media literate looks at the media critically and doesn't believe everything." (Alp)

"Media literate reads the book with a critical eye." (Yosun)

Another remarkable finding in Table 3 is that some of the students stated that they do not know the characteristics of the media literate. This situation is in parallel with the findings related to the knowledge of media literacy in Table 2. It is natural that a child who is not aware of media literacy cannot rank the characteristics of media literate.

Being able to define themselves as Media Literate or not

The findings regarding the responses of the students to the research question asked to determine their awareness are given in Table 4.

Table 4. Children's awareness of themselves

\begin{tabular}{lc}
\hline Being able to define themselves as Media Literate or not & $\boldsymbol{f}$ \\
\hline I am a Media Literate & 5 \\
\hline
\end{tabular}

\footnotetext{
† Emir: Participant students were given pseudonyms.
} 
According to the findings in Table 4, nearly half of the students describe themselves as media literate. Some of the students who did define themselves as media literate have expressed themselves as follows:

"I'm a media literate. I don't watch all cartoons. I choose the cartoons I love and watch them." (Maya)

"There are a lot of magazines and books, but I just read my favorite magazines and books. That's why I think I'm a media literate." (Gamze)

"I'm a media literate because I'm watching convenient programs for my age." (Emir)

Some of the students who said that they are not media literate have expressed themselves as follows:

"I think I'm not a media literate because I don't know how to be media literate." (Lale)

"I don't think kids can be a media literate. These are adults' work." (Maya)

\section{Discussion and Conclusion}

The aim of this study is to investigate the opinions of nine-year-old students on media literacy and media literate. Nearly half of the students in the study described media literacy as important having a time limit in the use of all media tools. Students' expressions show that the time limit often creates problems with their parents. There may be two reasons for this. First, as Degaetano (2007) states, with the industrialization, the newly formed culture entered the houses in an uncontrolled way through the media. This culture is not in line with the expectations of the society and the family. The elements of this culture enter the houses with the media prepared for children, but the messages do not correspond to the expectations of the parents. In this case, the family tries to control the situation by putting the time limit. A similar situation was supported by Arslan-Cansever's (2012) study in which she examined the effects of Internet on the socialization process of pre-adolescents in the context of parents. In this study, it was determined that the long-term use of Internet had a negative effect on the relationships of the adolescents with their parents, and that most of the parents had a discussion about the Internet usage with their children. In a study conducted by Lee, Bartolic and Vandewater (2009) in America, time constraints have emerged as one of the reasons affecting media usage. The second reason is related to the protectionist approach in media education. According to Halloran and Jones (1992), this approach claims that young people are vulnerable to the powerful and harmful effects of the media. The individual needs to be protected against these effects. In this respect, the approach considers individuals as passive. The conflict with the parent because of the time limitation is a situation raised especially for boys. The case may be explained by the socialization process in a gendered society as in Turkey. In the family, the boys are more tolerated than the girls. Boys are freer than girls in socialization process. This form of practice may cause males not to obey the parental authority. In the research, about two-thirds of the students defined media literacy as looking at the media critically. There are many studies emphasizing the importance of critical thinking in media literacy in the literature (Baker, 2012; Considine, 2008; Hobbs, 2011; Potter, 2005). Similarly, Hart (1991) argues that media literacy creates active media users who can think critically. Critical thinking skills are closely related to the way individuals are first raised in a family environment and then in society. This skill is that societies give to individuals that supports an individual's self-expression through their abilities to make their own free choices. Some researchers (Lim \& Smith, 2008; Kagitcibasi, 1996; 2002) have called these societies as individualist society. In contrast to these societies, collective societies (Lim \& Smith, 2008) are also essential to show individual behavior to society and to determine their own goals according to the expectations of society. It is meaningful that the participant students who grow up in a collective society match the media literacy with critical thinking. This situation can be considered as an extension of the educational level, socio-economic and sociocultural status of the parents in the schools where the research is conducted. In the research, it is important that approximately one third of the students answer media literacy definition as I do not know. As it is known, the child acquainted with media tools in the family environment during infancy (Erturk \& Gul, 2006; Tyner, 2009; Field, Muir, Pilon, Sinclair \& Dodwell, 1980). The family environment is important in developing a certain perception by gaining attitude, value, behavior and awareness of the individual on any subject. A study aimed at determining the perceptions of media and media literacy for children of nine years of age (Arslan-Cansever, 2013) revealed that the programs that children watch on television were mostly their parents' preferences. At the same time, it was determined that peer groups were effective in the selection of the types of activities performed by the children on the computer. Research has shown that children's ability to make their own choices about media and their perception of media literacy are not formed yet. Similarly, in this study, it can be said that some of the students who participated in the research did not have sufficient awareness about media literacy.

According to research findings, approximately two thirds of the students stated that media literate individuals can use media tools for educational purposes. This situation can be explained by the elements shaping the socialization process of the child in Turkish society. As a matter of fact, Aslan and Arslan-Cansever (2007; 2009a; 2009b; 2012) stated that collective values, individual dependence, status acquisition and adaptation to group values are the main values in 
Turkish society. Socialization of the child is realized within the framework of these values. As the academic success of the child is highly cared for by the society, the individual spends his childhood years being obliged to be successful. In recent years, even though the parents in the modern nuclear family structure have become more sensitive to the child's interests and abilities, the expectation of high academic success is still felt. The use of media tools for educational purposes may be associated with the processes Hobbs (2011) has set for media literacy. According to Hobbs (2011, p.12), media literacy processes consist of acquisition, analysis, reconstruction, reflection and action. Acquisition is the first step in the media literacy process. At this stage, the individual is expected to know how to find the various forms of the media, how to reach them and learn how to use them. In this research, knowing the use of media tools for educational purposes can be associated with the acquisition process. On the other hand, some of the students stated that the media literate was like a critic. Baker (2012), Potter (2005) and Hobbs (2011) emphasize the importance of critical thinking in media literacy. Critical thinking helps to recognize important details that are hidden in messages. Individuals can interpret different kinds of media messages through critical thinking. In the research, some of the students explained the characteristics of the media literate as I do not know. It is accepted that the parents and teachers play an important role in the development of media literacy awareness in childhood. However, there is a need for studies on the level of awareness of parents and teachers about media literacy. This is because parents and teachers are role models for children.

In the last section where the child's awareness of media literacy is questioned, almost half of the students think that they are media literate. On the other hand, there are students who are not sure whether they are media literate or not.

In this research, it was aimed to examine the students' views on media literacy and media literate. In the literature, there are developed scales for teacher candidates to determine the level of media literacy. However, there is a need for scales to measure the level of media literacy of children and their perceptions and attitudes. There are a limited number of scales developed for children in the literature. In the future, the field can focus on developing more scales that measure children's media literacy.

Parents and educational institutions have an important role in students' to gain media literacy ability starting from primary school. Media literacy in educational settings can be given within the framework of an independent course. If they cannot be done, they can be given within the framework of associating with other courses. In educational settings, teachers can receive in-service training seminars on media literacy. Similarly, for parents, these trainings can be given by practices such as parents' school.

\section{References}

Altun, A. (2010). Teaching of media literacy and its integration into social studies curricula (Unpublished doctoral dissertation). Gazi University Institute of Educational Sciences, Ankara, Turkey.

Anderson, D. R. (2013). Children and media: Cognitive development and education. In H. Yavuzer, \& M. R. Sirin (Eds.), Proceedings of 1st Turkey Children and Media Congress (pp. 77-89). Istanbul, Turkey: Cocuk Vakfi.

Arslan-Cansever, B. (2012). The effects of internet usage on relationship between adolescents and their parents. Duzce University Journal of Management and Education Sciences, 2(1).

Arslan-Cansever, B. (2013, April). Children's perceptions about media literacy. Paper presented at the TRT International Children and Media Congress -II, Izmir, Turkey.

Aslan, N., \& Arslan-Cansever, B. (2007). Parent- child interaction in participation in social activities at school (A crosscultural study). Ege Education Journal, 8(1), 113-130.

Aslan, N., \& Arslan-Cansever, B. (2009a). Effects of family socio-demographic characteristics on child participation in social activities at school: A comparative study between Turkey and the Netherlands. Journal of Theory and Practice in Education, 5(2), 210-226.

Aslan, N., \& Arslan-Cansever, B. (2009b). The primary school teachers' attitudes for creativity in education. Turkish Science Research Foundation, TUBAV Scientific Journal, 2(3), 333-340.

Aslan, N., \& Arslan-Cansever, B. (2012). Leisure Perceptions of Adolescents. Hacettepe University Journal of Education, 42, 23-35.

Aufderheide, P. (1993). Media Literacy. A Report of the National Leadership Conference on Media Literacy., Queenstown, MD: Aspen Inst.

Aufderheide, P. (2001). Media Literacy in the Information age: Current perspectives. In R. Kubey (Ed.), Media Literacy: from A report of the National Leadership Conference on Media Literacy (pp. 79-86). New Brunswick, NJ: Transaction.

Baker, F. W. (2012). Media literacy in the K-12 classroom. Washington, DC: ISTE Publishing.

Cakir, V., \& Cakir, V. (2010). Television addiction. Istanbul, Turkey: Literaturk. 
Cetinkaya, S. (2008). The importance of media literacy in the awareness-raising process for media users. (Unpublished master's thesis). Ankara University Institute of Social Sciences, Ankara, Turkey.

Christensen, L. B., Johnson, R. B., \& Turner, L. A. (2015). Research methods: Design and analysis (A. Aypay, Trans. Ed.), Ankara, Turkey: Ani.

Considine, D. (2008). Case for media literacy in today's schools. Retrieved from http://www.medialit.org/reading_room/article368.html.

Creswell, J. W. (2009). Research design: Qualitative, quantitative and mixed approaches. Thousands Oaks, CA: London Sage Publications, Inc.

Degaetano, G. (2007). Parenting well in media age. (Trans. N. P. Ocel), Ankara, Turkey: Nobel.

Ersoy, A. F. (2016). Phenomenology. In A. Saban \& A. Ersoy (Eds.). Qualitative research patterns in education (pp.51105). Ankara, Turkey: Ani.

Erturk, Y. D., \& Gul, A. A. (2006). Don't give your child to television, become media literate. Ankara, Turkey: Nobel.

Field, J., Muir, D., Pilon, R., Sinclair, M., \& Dodwell, P. (1980). Infants' orientation to lateral sounds from birth to three months. Child Development, 51(1), 295- 298.

Gander, M. J., \& Gardiner, H. W. (2001). Child and adolescent development (4th ed., A. Donmez, N. Celen \& B. Onur, Trans.). Ankara, Turkey: Imge.

Gregory, E. M. (2013). Media use of children: a positive psychology approach. In H. Yavuzer, \& M. R. Sirin (Eds.), Proceedings of 1st Turkey Children and Media Congress (pp. 77-89). Turkey: Istanbul: Cocuk Vakfi.

Halloran, J. D., \& Jones, M. (1992). The inoculation approach. In M. Alvarado \& O. Boyd-Barrett (Eds.), Media education: An introduction (pp.10-13). London, UK: BFI.

Hart, A. (1991). Understanding the media: A practical guide. London, UK: Routledge.

Hobbs, R. (2004). A Review of School-based Initiatives in Media Literacy Education. Retrieved from http://abs.sagepub.com/cgi/content/abstract/48/1/42.

Hobbs, R. (2011). Digital and media literacy. California, CA: Sage.

Kagitcibasi, C. (1996). Family and human development across cultures: A view from the other side. Hillsdale, NJ: Lawrence Erlbaum.

Kagitcibasi, C. (2002). A model of family change in cultural context. In W. J. Lonner, D. L. Dinner, S. A. Hayes, \& D. N. Sattler (Eds.), Online Readings in Psychology and Culture. Washington, DC: Washington University, Center for Cross-Cultural Research,

Kincal, R., \& Kartal, O. Y. (2009). Media literacy education. National Education Journal, (181), 318-330.

Koc, E. (2016). An application for media literacy education in Turkey (Unpublished doctoral dissertation). Maltepe University Institute of Social Sciences, Istanbul, Turkey.

Lee, S. J., Bartolic, S., \& Vandewater, E. A. (2009). Predicting children's media use in the USA: Differences in crosssectional and longitudinal analysis. British Journal of Developmental Psychology, 27(1), 123-143.

Lim, S., \& Smith, J. (2008). The structural relationships of parenting style, creative personality, and loneliness. Creativity Research Journal, 20(4), 412-419.

Lindstrom, M., \& Seybold, P. B. (2003). Children's of today's world purchasing power, consumption preferences and relations with brands (A. Ozer \& D. Gunkut, Trans. Eds.), Istanbul, Turkey: CSA Publication Agency.

Merriam, S. B. (2013). A guide to qualitative research, design and implementation (S. Turan, Trans. Ed.). Ankara, Turkey: Nobel.

Miles, M. B., \& Huberman, A. M. (1994). Qualitative data analysis: An expanded sourcebook. Thousand Oaks, CA: Sage.

Patton, M. Q. (2014). Qualitative research and evaluation methods (M. Butun \& S. B. Demir, Trans. Eds.). Ankara, Turkey: Pegem.

Pekman, C. (2007). Media literacy in the European Union. In N. Turkoglu, M.C. Simsek (Eds), Media literacy (pp. 40-49). Istanbul, Turkey: Kalemus.

Piotrowski, J. T., Vossen, H. G. M., \& Valkenburg, P. M. (2013). Media and child development. In H. Yavuzer, \& M. R. Sirin (Eds.), Proceedings of 1st Turkey Children and Media Congress. Istanbul, Turkey: Cocuk Vakfi.

Postman, N. (1994). Amusing ourselves to death (O. Akinhay, Trans.). Ankara, Turkey: Ayrinti. 
Potter, W. J. (2005). Media literacy (3rd ed.). California, CA: Sage.

Rideout, V., Foehr, U. G., \& Roberts, D. F. (2010). Generation M2: media in the lives of 8 to 18 years olds. Menlo Park, CA: Henry J. Kaiser Family Foundation.

Tan, 0. (2015). Media literacy education: A sample research with respect to student, teacher and family (Unpublished doctoral dissertation). Akdeniz University, Antalya, Turkey.

Tyner, K. (1998). Literacy in a digital world: Teaching and learning in the age of information. Mahwah, NJ: Lawrence Erlbaum Associates.

Tyner, K. (2009). Can your students read TV? Retrieved from http://www.medialit.org/reading_room.html.

Winahyu, R. A. E., \& Djono, L. A. S. (2018). The media literacy in 21st century: Role of teacher in historical learning. International Journal of Multicultural and Multireligious Understanding (IJMMU), 5(4), 363-369.

Valkenburg, P. M., \& Vroone, M. (2004). Developmental changes in infants' and toddlers' attention to television entertainment. Communication Research, 31(3), 288-311.

Yildirim, A., \& Simsek, H. (2008). Qualitative research methods. Ankara, Turkey: Seckin. 